\title{
A Simplified Approach for Implementing Capital Gain Tax in Stock Marketing
}

\author{
Sivarajah Mylevaganam \\ Spatial Sciences Laboratory, Texas A\&M University, College Station, TX, USA \\ Email: sivaloga@hushmail.com
}

How to cite this paper: Mylevaganam, S. (2016) A Simplified Approach for Implementing Capital Gain Tax in Stock Marketing. Open Journal of Applied Sciences, 6, 868-892.

http://dx.doi.org/10.4236/ojapps.2016.613076

Received: November 19, 2016

Accepted: December 23, 2016

Published: December 26, 2016

Copyright $\odot 2016$ by author and Scientific Research Publishing Inc. This work is licensed under the Creative Commons Attribution International License (CC BY 4.0).

http://creativecommons.org/licenses/by/4.0/

\begin{abstract}
The sustainability of a country inevitably depends on proper taxation system. To date, there are many taxes implemented by the ruling authorities of a country. The taxes that are sourced from stock markets or share markets are paramount to better govern a country. The capital gain tax (CGT), which is incurred in disposing the shares or stocks owned by an investor or an institution, is one of the taxes implemented in stock markets. Though in the past many attempts have been made to properly streamline the CGT, the methodologies or the approaches used in the implementation of CGT, even in the United States, are not well-grounded from a scientific point of view. Therefore, in this paper, a simplified approach based on the assumption that the CGT is implemented on a yearly basis is proposed. The CGT is calculated for each stock owned by an investor or an institution. The approach is implemented using an open access platform: AMP (Apache-MySQL-PHP). Subsequently, the proposed approach is tested using some hypothetical data. The proposed approach, which is easy-to-use, practical and un-biased, is of use to any country that is willing to progress towards the sustainability. Moreover, the proposed approach with the current technology will enhance the developing nations which have large size of informal economy, on designing and implementing effective tax policies and administrations.
\end{abstract}

\section{Keywords}

Stock Market, Capital Gain Tax, Opportunity Cost, Taxation System, Database, MySQL, PHP, Share Market, Economy, Sustainability

\section{Introduction}

The sustainability of a country is heavily underscored by the principle of accounting that is defined by revenue and expenses. On the other hand, an attempt to raise the lev- 
el of development from the status of "developing" to "developed", as defined by [1], may substantially peak the deficit between the revenue and the expenses. Therefore, to overcome this issue, the ruling authorities of a country may seek many options. Raising the income or revenue is one of those options, which is considered fruitful in the long run. Though there may be many paths to raise the income or revenue, taxes through properly implemented system [2] [3] [4] [5] predominantly favor among others.

To date, there are different kinds of taxes [3] [6] [7] [8], such as income tax, capital gains, corporate tax, property tax, and value added tax, implemented by countries to generate revenue [8] [9]. Generally, these taxes are pooled under two main categories, namely direct and indirect taxes. Among all the taxes raised by the ruling authorities of a country, the capital gain tax (CGT), one of the direct taxes, paid by the investors/institutions in a share market, is one of the primary sources of revenue [6] [7].

The CGT in share marketing is the tax that is incurred in disposing the shares or stocks owned by an investor or an institution [6] [7] [10]. The rate at which the CGT is applied may vary from one country to another. The rate may also vary from individuals to institutions [6] [7] [10]. The way that the CGT is implemented may also vary from country to another, as some countries have a separate and a distinct tax on capital gains in stock marketing [10]. For example, in Singapore, there is no capital gains tax. For professional traders and those who trade frequently, the profit is considered a sourced income in Singapore and subject to tax [7]. In Taiwan, the implementation of CGT was on and off, though with an anticipation of generating more revenue, a new CGT act on transactions of securities was re-introduced in 2013 [6]. In Canada, in response to a report that recommended to tax capital gains like other forms of income, depending on those who hold the asset (individual or business), capital gains are taxed at either personal or corporate income tax rates [10]. However, as per [10], in 2013, out of 34 countries, including Canada, in Organization for Economic Cooperation and Development (OECD), 11 of them (e.g., New Zealand, Belgium, and Netherlands) did not levy on capital gains. In the United States, the CGT rate depends on both the investor's tax bracket and the amount of time the investment was held [11]. As of 2016, short-term capital gains, which are defined as gains from investments held for a year or less before being sold, are taxed at the investor's ordinary income tax rate. On the other hand, long-term capital gains from investments held for more than one year are taxed at generally lower rates [11]. Moreover, for individuals, a net loss from investments can be claimed as a tax deduction against ordinary income. The maximum permitted claim is USD 3000 per year (USD 1500 in the case of a married individual filing separately). Any remaining net loss can be carried over and applied against gains in future years [11].

As presented in the foregone paragraph and as underscored in the literature [6] [7] [8] [10] [11], the methodologies or the approaches used in the implementation of CGT, even in the United States, are not well-grounded from a scientific point of view. Moreover, it is not true that higher tax rate will maximize the revenue [5]. On the other hand, it is well documented that the implementation of CGT comes with some consi- 
derable economic costs, such as bunching, lock-in, and tax avoidance [6] [10]. Therefore, there exists an optimum tax rate or a feasible domain on capital gains in stock marketing. Having said this, such an optimum rate may not become visible unless the methodologies or the approaches used in the implementation of CGT are based on fundamental. Otherwise, the implementation of CGT will be on and off with the change of rulers of a country, without reforming the policies on CGT in a sustainable manner. In return, this may cause many investors to become wary of any investments associated with the capital gains tax due to the increase in the investment cost [6]. Therefore, the objective of this paper is to propose and test a simplified approach/methodology, which is easy-to-use, practical, un-biased, and of use to any country that is willing to progress towards the sustainability, for implementing CGT in stock market.

\section{Methodology}

The detailed methodology of the proposed approach is shown in Figure 1. Figure 1

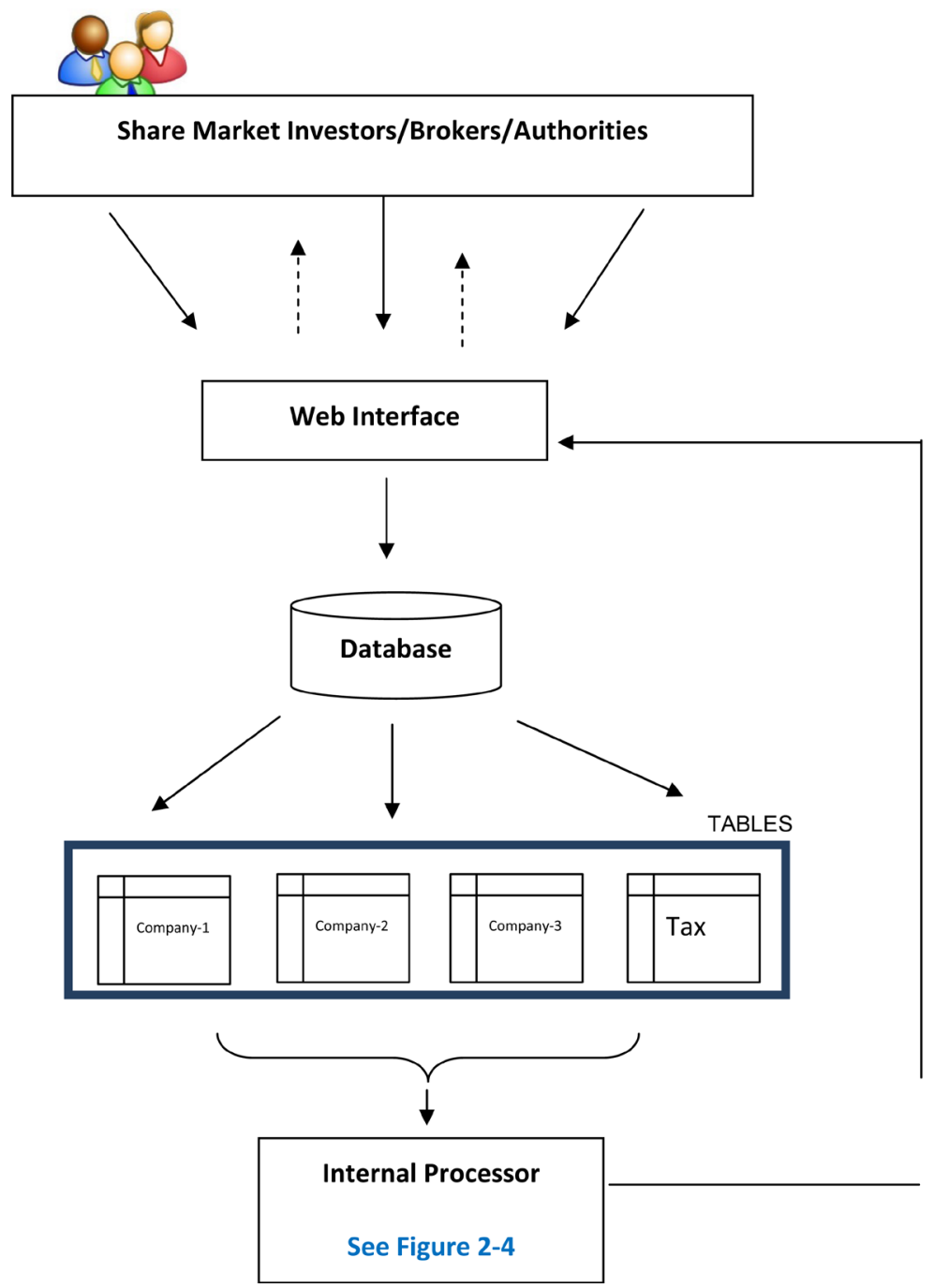

Figure 1. The detailed implementation of the proposed approach. 
is further explained through Figures 2-4. As shown in Figure 1, initially, the user inputs are collected through a web interface that is developed using an open access platform: AMP (Apache-MySQL-PHP). Subsequently, the inputs are passed to a database to get the records associated with the investor of interest.

To store the transactions of an investor on public quoted companies, few tables are developed within the database. Each table in the database represents one of the listed companies bought by the investor. The rows of the tables represent the transactions. The detail structure of the table is placed in Table 1. To avoid deviating from the proposed approach, the details such as the primary keys and other relational matters of the database are not presented in this paper. As shown in Table 1, few columns are created to store the number of shares bought/sold, the date of transaction, total amount of money paid for the transaction and the nature of the transaction (i.e., whether the transaction was to sell the stocks or to buy the stocks). For example, as shown in Table 1, on November 10, 2016, the investor has bought 100 shares of one of the listed companies for a total price of CGR 9888.00 (to avoid basing this paper to a particular country, a new currency code (CGR) is introduced). This amount includes the fees that are applicable for this transaction. These fees may include the brokerage, government commissions and other fees that are applicable. This type of table is developed for each

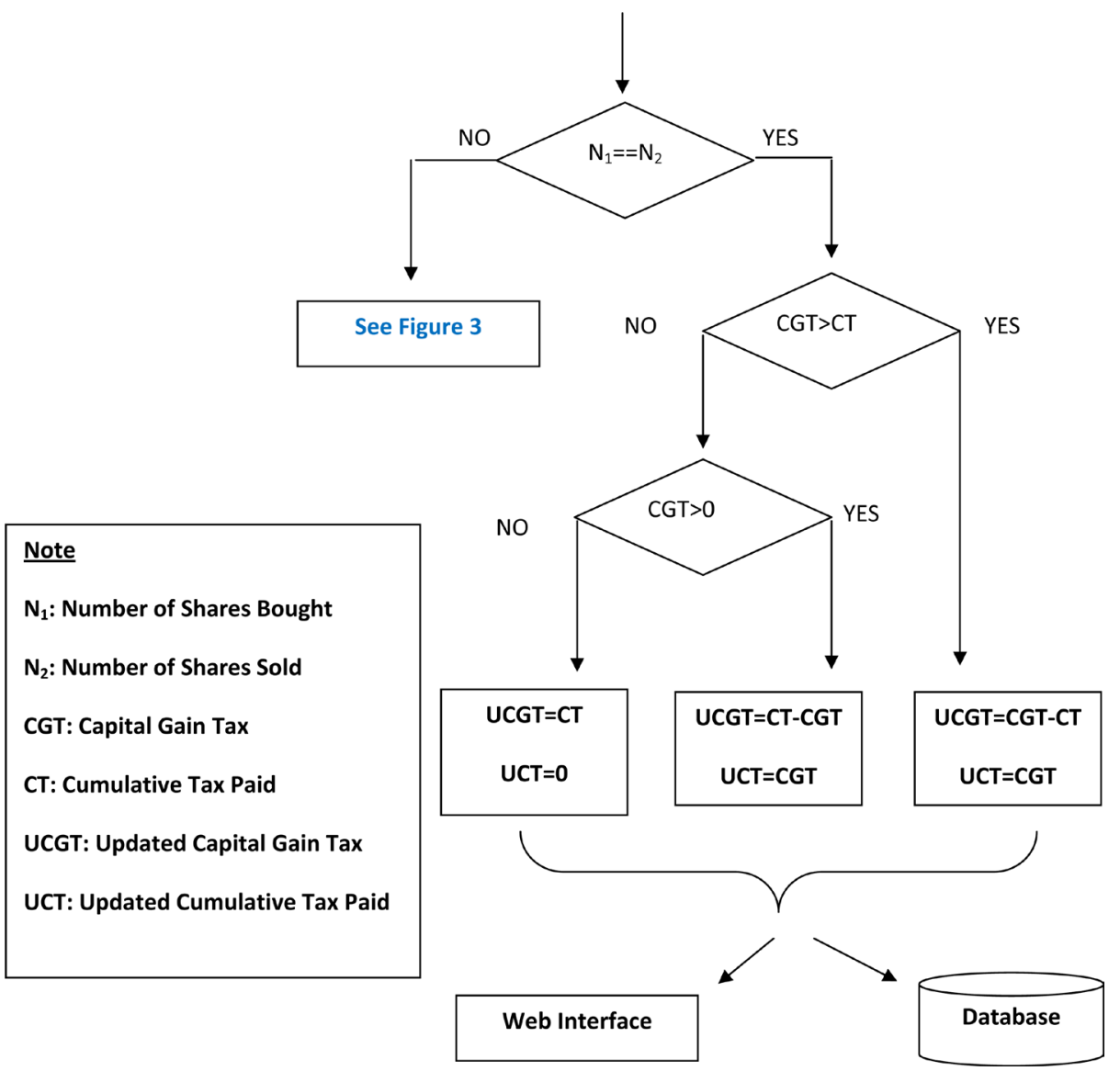

Figure 2. The proposed approach on CGT for Scenario-1. 


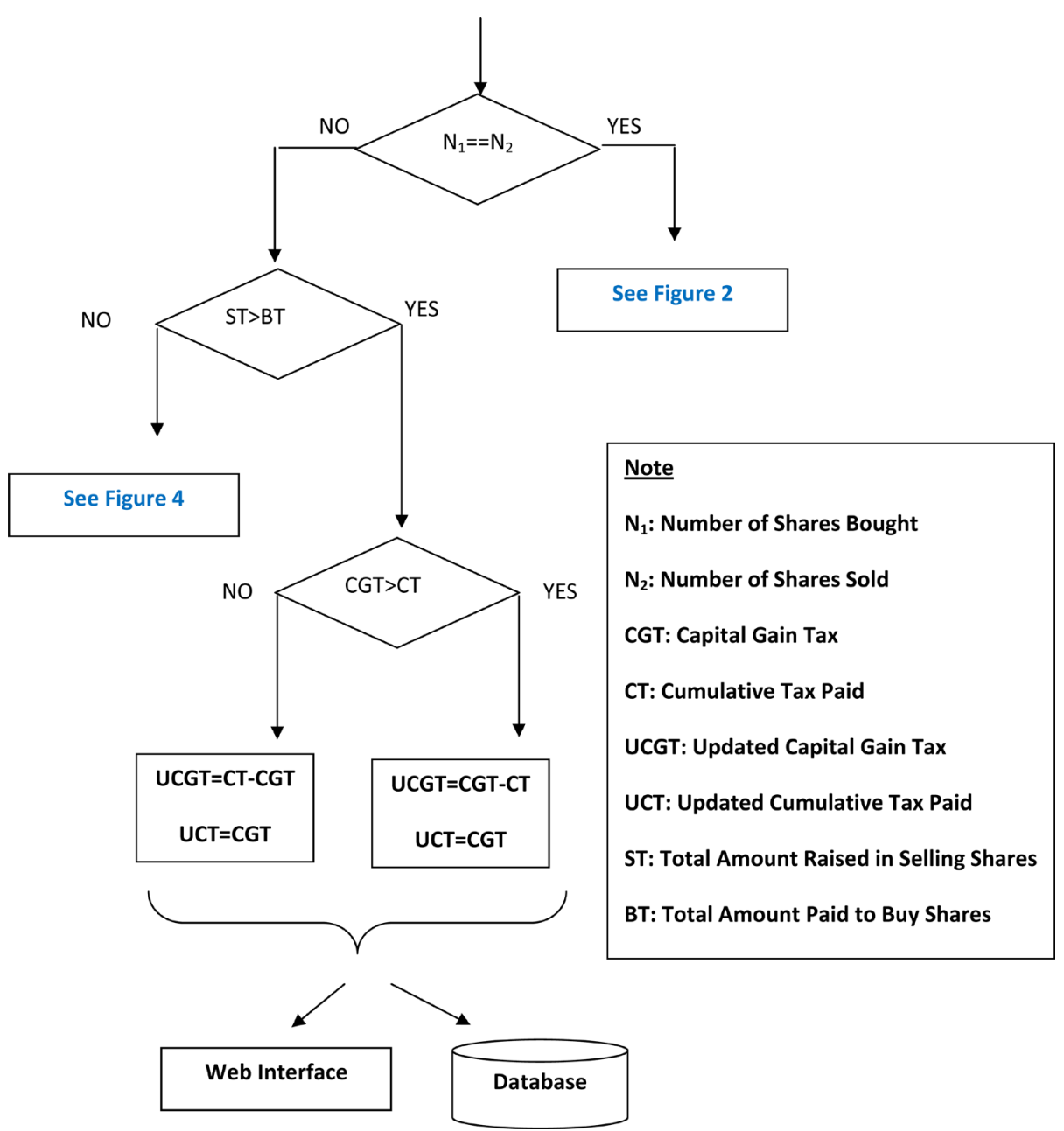

Figure 3. The proposed approach on CGT for Scenario-2.

company that is bought by an investor. The database also has a table (Table 2) to store the cumulative tax paid by the investor for each stock owned by the investor. As shown in Table 2, there are two columns. The first column is the company code that uniquely identifies each of the listed companies. The second column is to store the cumulative tax paid by the investor since the share market account was opened. For example, as shown in Table 2, the investor owns stocks from companies, namely CHES and BOSS. The total amount of cumulative tax that the investor has paid in investing in CHES and BOSS is CGR 123 and CGR 234, respectively.

As shown in Figure 1, the information from the tables is passed to an internal processor that is composed of three scenarios. These scenarios are presented in Figures 2-4. Moreover, the details of these scenarios are explained in section 2.1, 2.2, and 2.3.

\subsection{Scenario-1 (i.e., the Number of Shares Bought Is Equal to the Number of Shares Sold)}

The first scenario is based on the available stocks. For the year in concern, if the number of shares bought is equal to the number of shares sold (i.e., the investor doesn't hold 


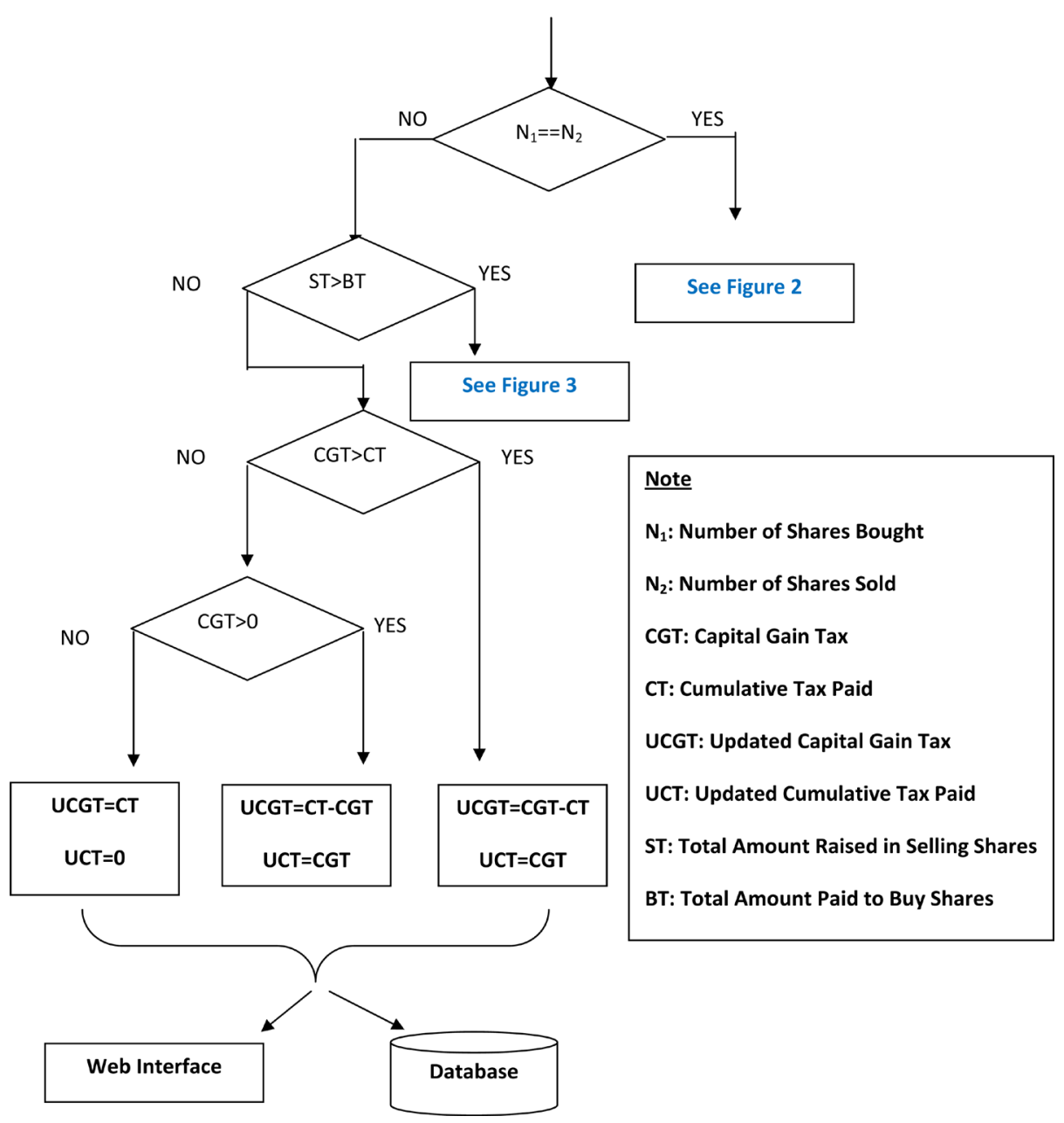

Figure 4. The proposed approach on CGT for Scenario-3.

Table 1. The share transactions of an investor in one of the listed companies.

\begin{tabular}{cccc}
\hline Date & Number of Shares & Amount (CGR) & Type \\
\hline $10 / 11 / 2016$ & 100 & 9888.00 & $\mathrm{~B}$ \\
$11 / 12 / 2016$ & 75 & $12,356.78$ & $\mathrm{~S}$ \\
\hline
\end{tabular}

Table 2. The cumulative CGT paid by an investor in a share market.

\begin{tabular}{cc}
\hline Company Code & Cumulative Tax Paid (CGR) \\
\hline BOSS & 234 \\
CHES & 123
\end{tabular}

any shares unsold), then the investor is directed as per Figure 2. This is the best the scenario that a government can have to avoid any complication in determining the CGT. Under this scenario, the total amount of money raised in selling the shares minus the total amount money paid to buy the shares is used to calculate the net earnings. Under this scenario, three conditions are tested to estimate the CGT. Under the first condition (i.e., YES-YES in Figure 2), it is tested if the cumulative tax paid until the 
year of interest is less than the computed CGT. On the other hand, two conditions are tested if the computed CGT is less than the cumulative tax paid until the year of interest. The first condition tests (i.e., YES-NO-YES in Figure 2) if the computed CGT is greater than zero. If the computed CGT is greater than zero, then the government is liable to pay the difference. On other hand if the computed CGT is less than zero (i.e., YES-NO-NO in Figure 2) then total amount of cumulative tax that has been paid until the year in concern shall be returned to the investor.

\subsection{Scenario-2 (i.e., Failure of Scenario-1 and the Total Amount of Money Raised in Selling Shares Is Greater than the Total Amount of Money Paid to Buy Shares)}

The scenario- 2 is activated when the scenario-1 is failed (i.e., the number of shares bought is not equal to the number of shares sold). Under this scenario, even with few shares left unsold, the total amount of money raised in selling the shares must be greater than the total amount of money paid to buy the shares. In other words, the investor will have positive net earnings. Therefore, under this scenario, the total CGT is calculated without considering the remaining shares left unsold. However, under this scenario, two conditions are tested as shown in Figure 3 (i.e., NO-YES-YES and NO-YES-NO in Figure 3).

\subsection{Scenario-3 (i.e., Failure of Scenario-1 and Scenario-2)}

The scenario-3 is implemented when the first two scenarios are failed. This happens when the number of stocks owned by an investor is not equal to zero. In other words, the number of shares bought is not equal to number of stocks sold until the year of interest. Therefore, the value of the remaining shares is unknown at the time of tax calculation. Considering this, it may be feasible to have two options under this scenario. As long as the investor keeps holding the remaining shares, the investor may not be required to pay the tax. This has both positive and negative impacts. Should the government decide to eliminate the current taxation system on CGT, the investor will be benefitted by not paying the tax. The second option is the remaining unsold shares are virtually valued based on the current market price of the stock under consideration (i.e., had the investor disposed the unsold shares at the current market price, what the total value of the remaining shares would be). The virtual valuation of the unsold shares will help to estimate the capital gain or loss realized for the year under consideration. With the market value of the shares, if the investor gains, then the CGT is implemented even if the investor doesn't sell the shares. On other hand, if the market price of the remaining unsold shares falls, the investor has the option to claim the tax paid for the previous years. The method of virtual valuation is really useful for the government of a country to avoid large-scale investors evading taxes.

\section{The Development of the Proposed Approach}

The web interface of the proposed approach on CGT in a stock market is shown in Figure 5. The web interface is developed using an open access platform: AMP (Apache- 


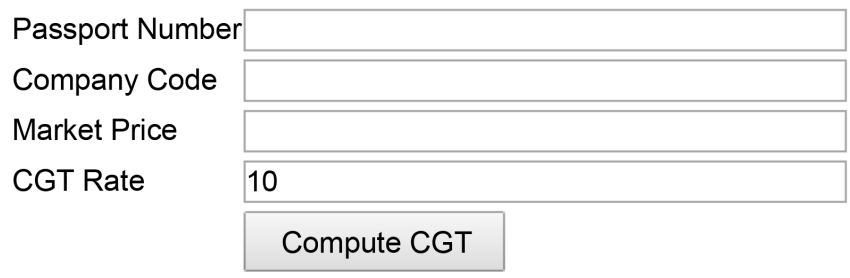

Figure 5. The Web interface of the proposed approach on CGT.

MySQL-PHP). To identify the investor or the institution, a unique number (e.g., passport number) is entered through the web interface. The web interface also requires the company code, CGT rate, and the market price of the company that is evaluated for the CGT. The current version of the web interface doesn't populate the market price and the CGT rate, though these details could be potentially populated automatically based on the existing databases that are used to store the daily status of a stock market in a country. The detailed implementation of the web interface is discussed below. To facilitate the reader, the complete source code of the interface is provided in Appendix.

In the web interface shown in Figure 5, as shown in the below code snippet, the inputs are collected through form elements (i.e., input tags). Upon submission of the form, the form action is posted to the same PHP page, instead of directing to a new PHP file. This is accomplished using the \$_SERVER array with "PHP_SELF" as the index.

1. $\langle$ HTML $>$

2. $<$ form action="<?=\$_SERVER['PHP_SELF']?>" method="post">

3. <table style="width: $100 \%$, text-align:center">

4 .

5. $<\operatorname{tr}>$

6. $\quad<\mathrm{td}>$ Passport Number $</ \mathrm{td}>$

7. $<$ td $><$ input name="NIC" type="text" style="width: 300px" $\mid><$ br $/></$ td $>$

8. $</ \operatorname{tr}>$

9. $\quad .$.

10.

11. $<\operatorname{tr}>$

12. $<\mathrm{td}></ \mathrm{td}>$

13. $<$ td $><$ input style="width: 130px; height: 30px" type="submit" name="submit" value="Compute CGT" $\mid>\langle$ br $/></$ td $>$

14. $</$ tr $>$

15.

16. $</$ table $>$

17. $</$ form $>$

18. $</$ HTML $>$

Initially, as shown in the below code snippet, using an if-block, it is checked whether the posting of the web page comes from the "submit" button. Within this if-block, the form variables are stored for the processing of CGT. For example, as shown in the be- 
low code snippet, the company code that is posted from the web interface is stored in a PHP variable named \$companyCode.

1. if (isset(\$_POST['submit']))

2. \{

3.

4. $\quad$ \$companyCode $=\$$ \$POST ['CODE'];

5. $\$$ NICCode $=\$$ _POST['NIC'];

6. $\quad$ \$CGTCode $=\$$ \$POST['CGTR'];

7. $\$$ MktPrice $=\$$ _POST['MktPrice'];

8.

9. //The rest of the source code goes here

10.

11. $\}$

Subsequently, the PHP function mysql_connect() was used to connect to the MySQL server. If the connection is successful, the database of the investor of interest is selected using the PHP function mysql_select_db(). The passport number (\$NICCode) of the investor is specified as the input argument to mysql_select_db(). Then, as shown in the below code snippet, a SQL query is executed using mysql_query(). In the SQL query, a select statement is used to fetch the total number of shares bought by the investor, total amount of money paid by the investor to buy the shares, and the average share price of the shares bought by the investor. The queried result is stored in a PHP variable for further processing. Similarly, a SQL query is executed to get the details that are related to the shares sold by the investor.

1. $\$$ query $=$ "SELECT $\operatorname{sum}($ Amount $) /$ Sum(NShares), Sum(NShares), Sum(Amount) FROM". \$stockCode." WHERE Type='B'";

2. $\quad$ \$result $=$ mysql_query $(\$ q u e r y) ;$

3. $\quad$ \$buyAverage $=$ mysql_result $($ \$result, 0, "sum(Amount)/Sum(NShares)");

4. \$buyShares $=$ mysql_result $($ \$result, 0 , "sum(NShares)");

5. $\quad$ \$buyTotal = mysql_result (\$result, 0, "sum(Amount)");

The below code snippet is used to get the information from the MySQL table that holds the tax details of the investor. The SQL query returns the cumulative tax paid by the investor for the stock of interest.

1. \$query = "SELECT CumulativeTaxPaid FROM taxinfo WHERE Company="'. \$stockCode."'";

2. $\$$ result $=$ mysql_query $(\$ q u e r y) ;$

3. \$taxPaid = mysql_result( $\$$ result, 0 , "CumulativeTaxPaid");

As shown in Appendix, the proposed approach is housed within an if-elseif-else block. The scenarios that are discussed in Section 2.0 are formed within this if-elseif-else block. The if-block of this if-elseif-else block is used to form the scenario-1 discussed in Section 2.1. The elseif-block of this if-elseif-else block is used to form the scenario-2 discussed in Section 2.2. The else-block of this if-elseif-else block is used to form the scenario-3 discussed in Section 2.3.

As shown in the below code snippet, the scenario-1 discussed in Section 2.1 is 
formed with an if-block. The condition is based on the number of shares bought and the number shares sold. \$sellShares and \$buyShares are the PHP variables that are used to store the number of shares sold and the number shares bought, respectively. Within this if-block, a PHP variable named \$totalGainLoss is used to store the net amount gained or lost from investing in this stock. Subsequently, the PHP variable named \$CGT is used to store the CGT for this stock for the year in concern. The CGT is a product of \$totalGainLoss and \$rateCGT which is the PHP variable that is used to store the tax rate posted through the web interface.

1. if $((\$$ sellShares- $\$$ buyShares $)==0)\{$

2. \$totalGainLoss $=\$$ sellTotal- $\$$ buyTotal;

3. $\$ C G T=\$$ totalGainLoss ${ }^{\star} \$$ rateCGT/100;

4. $\quad \ldots$

5. $\}$

Within the above if-block, as shown in Figure 2, an if-else block is used to test the value of the computed CGT against the cumulative tax paid by the investor. The below code snippet shows the if-block (i.e., YES-YES in Figure 2) that is used to test whether the computed CGT is greater than the cumulative tax paid by the investor until the year in concern.

1. if $(\$ C G T>\$$ taxPaid $)\{$

2. $\quad$ echo " $<$ B $>$ Remarks: $</ \mathrm{B}><\mathrm{BR} />$ ";

3. $\quad \$ C G T U$ pdated $=\$ C G T-\$$ taxPaid;

4. $\quad$ echo "Your capital gain tax is ".\$CGTUpdated;

5. $\$$ taxNewPaid $=\$ C G T$;

6. $\quad$ \$query $=$ "UPDATE 'taxinfo' SET 'CumulativeTaxPaid’=".\$taxNewPaid." WHERE company="'.\$stockCode."'";

7. $\quad$ \$result $=$ mysql_query $($ \$query);

8. echo " $<\mathrm{BR} />$ ";

9. $\quad$ echo " $<\mathrm{BR} />$;

10. \}

As shown in the below code snippet, within the else-block (i.e., YES-NO in Figure 2) of the above if-block (i.e., YES-YES in Figure 2), another if-else block (i.e., YES-NO-YES or YES-NO-NO in Figure 2) is formed to test the sign of the computed CGT. Based on the sign of the computed CGT, the value of the computed CGT and cumulative tax paid are updated. Appendix has the complete source code of this implementation.
1. else \{
2. $\quad$ if $(\$ C G T>0)\{$
3. $\quad \ldots$
4. $\quad\}$
5. else\{
$6 . \quad \ldots$
7.
8. $\quad\}$
9. $\}$ 
To form the scenario-2 discussed in Section 2.2, the elseif-block of the if-elseif-elseblock is used. This block is used to test the whether the total amount of money raised in selling the shares is greater than the total amount of money paid to buy the shares. The complete source code for this elseif-block is provided in Appendix. The scenario-3 discussed in Section 2.3 is formed with an else-block of the if-elseif-else-block discussed previously. Within this else-block, the remaining unsold shares are valued using the market price of the share. The PHP variable named \$PossibleValue is used to store the possible amount of money that would be raised if the remaining shares were sold at the prevailing market price of the share. The inner implementation within this else-block is provided in Appendix.

1. else

2. \{

3. $\quad$ remainingShares $=\$$ buyShares- $\$$ sellshares;

4. $\$$ PossibleValue $=(\$ M k t \text { Price }-\$ M k t P r i c e * \$ \text { stockCommission } / 100)^{*} \$$ remaining Shares;

5. \$totalGainLoss $=\$$ sellTotal- $\$$ buyTotal $+\$$ PossibleValue;

6. $\$ C G T=\$$ totalGainLoss ${ }^{\star} \$$ rateCGT $/ 100$;

7.

8.

9. $\}$

\section{The Application of the Proposed Approach}

To test the scenarios presented in Section 2.0, as placed in Tables 3-10, few transactions of stocks are recorded. The tests are based on three investors', namely investor-A, investor- $\mathrm{B}$, and investor- $\mathrm{C}$, investments in CHES, BOSS, and RESS, respectively. For demonstration purpose, the CGT rate is assumed to be $10 \%$ of the net earnings. The

Table 3. The portfolio of investor-A on December 31, 2012.

\begin{tabular}{cccc}
\hline Date & Number of Shares & Amount (CGR) & Type \\
\hline $08 / 10 / 2012$ & 100 & 8089.60 & $\mathrm{~B}$ \\
$08 / 14 / 2012$ & 100 & 7887.36 & $\mathrm{~B}$ \\
$10 / 10 / 2012$ & 150 & $13,348.80$ & $\mathrm{~S}$ \\
$10 / 11 / 2012$ & 50 & 4696.80 & $\mathrm{~S}$ \\
\hline
\end{tabular}

Table 4. The portfolio of investor-A on December 31, 2013.

\begin{tabular}{cccc}
\hline Date & Number of Shares & Amount (CGR) & Type \\
\hline $08 / 10 / 2012$ & 100 & 8089.60 & $\mathrm{~B}$ \\
$08 / 14 / 2012$ & 100 & 7887.36 & $\mathrm{~B}$ \\
$10 / 10 / 2012$ & 150 & $13,348.80$ & $\mathrm{~S}$ \\
$10 / 11 / 2012$ & 50 & 4696.80 & $\mathrm{~S}$ \\
$03 / 12 / 2013$ & 100 & $11,123.20$ & $\mathrm{~B}$ \\
$11 / 12 / 2013$ & 100 & 9888.00 & $\mathrm{~S}$ \\
\hline
\end{tabular}


Table 5. The portfolio of investor-A on December 31, 2014.

\begin{tabular}{cccc}
\hline Date & Number of Shares & Amount (CGR) & Type \\
\hline $08 / 10 / 2012$ & 100 & 8089.60 & $\mathrm{~B}$ \\
$08 / 14 / 2012$ & 100 & 7887.36 & $\mathrm{~B}$ \\
$10 / 10 / 2012$ & 150 & $13,348.80$ & $\mathrm{~S}$ \\
$10 / 11 / 2012$ & 50 & 4696.80 & $\mathrm{~S}$ \\
$03 / 12 / 2013$ & 100 & $11,123.20$ & $\mathrm{~B}$ \\
$11 / 12 / 2013$ & 100 & 9888.00 & $\mathrm{~S}$ \\
$04 / 15 / 2014$ & 100 & $10,112.00$ & $\mathrm{~B}$ \\
$12 / 17 / 2014$ & 100 & 4944.00 & $\mathrm{~S}$ \\
\hline
\end{tabular}

Table 6. The portfolio of investor-B on December 31, 2012.

\begin{tabular}{cccc}
\hline Date & Number of Shares & Amount (CGR) & Type \\
\hline $01 / 13 / 2012$ & 100 & $10,112.00$ & $\mathrm{~B}$ \\
$08 / 14 / 2012$ & 75 & $11,124.00$ & $\mathrm{~S}$ \\
\hline
\end{tabular}

Table 7. The portfolio of investor-B on December 31, 2013.

\begin{tabular}{cccc}
\hline Date & Number of Shares & Amount (CGR) & Type \\
\hline $01 / 13 / 2012$ & 100 & $10,112.00$ & $\mathrm{~B}$ \\
$08 / 14 / 2012$ & 75 & $11,124.00$ & $\mathrm{~S}$ \\
$03 / 12 / 2013$ & 100 & $10,112.00$ & $\mathrm{~B}$ \\
$11 / 12 / 2013$ & 95 & 9863.28 & $\mathrm{~S}$ \\
\hline
\end{tabular}

Table 8. The portfolio of investor-C on December 31, 2012.

\begin{tabular}{cccc}
\hline Date & Number of Shares & Amount (CGR) & Type \\
\hline $08 / 10 / 2012$ & 100 & $10,112.00$ & $\mathrm{~B}$ \\
$08 / 14 / 2012$ & 75 & 8157.6 & $\mathrm{~S}$ \\
On December 31, 2012, the market price of RESS is CGR 90 and the transaction fee is $1.12 \%$ &
\end{tabular}

Table 9. The portfolio of investor-C on December 31, 2013.

\begin{tabular}{cccc}
\hline Date & Number of Shares & Amount (CGR) & Type \\
\hline $08 / 10 / 2012$ & 100 & $10,112.00$ & $\mathrm{~B}$ \\
$08 / 14 / 2012$ & 75 & 8157.6 & $\mathrm{~S}$ \\
On December 31, 2013, the market price of RESS is CGR 80 and the transaction fee is $1.12 \%$
\end{tabular}

Table 10. The portfolio of investor-C on December 31, 2014.

\begin{tabular}{cccc}
\hline Date & Number of Shares & Amount (CGR) & Type \\
\hline $08 / 10 / 2012$ & 100 & $10,112.00$ & B \\
$08 / 14 / 2012$ & 75 & 8157.6 & $S$ \\
On December 31, 2014, the market price of RESS is CGR 60 and the transaction fee is $1.12 \%$ & \\
\hline
\end{tabular}

section 4.1-4.3, 4.4-4.5, and 4.6-4.8 test the scenarios presented in section 2.1, 2.2, and 2.3 , respectively. 


\subsection{YES-YES in Figure 2}

To test the scenario-1, consider an investor (investor-A) who opened an account to trade stocks in January 2012. This investor's transactions in one of the listed companies (CHES) are placed in Table 3. As per Table 3, the investor has bought 200 shares of CHES. The dates of transactions are shown in Table 3. By December 31, 2012, the investor has sold all the shares. In other words, the portfolio of investor-A is left with zero unsold shares of CHES. Therefore, as per the proposed methodology, assuming that that the CGT is implemented every year on December 31, 2012, this investor is conditioned as per scenario- 1 that occurs when the number of shares bought is equal to the numbers sold for the year of interest. As per Table 3, the total amount of money that the investor has paid to purchase the shares is CGR $15,976.96(=8089.60+7887.36)$. However, the total amount of money that the investor has raised in selling all the shares is CGR 18,045.60 $(=13,348.80+4696.80)$. Therefore, the investor has gained from his investment in CHES in 2012. The CGT for this investor is CGR $206.86(=(18,045.60-$ $15976.96)^{\star} 10 / 100$. Using the web interface and the implemented approach, the investor will be displayed as shown in Figure 6 .

\subsection{YES-NO-YES in Figure 2}

The portfolio of investor-A on December 31, 2013, is placed in Table 4. As shown, like in 2012, the investor is able to sell all the stocks bought. Therefore, to tax this investor in 2013, the scenario-1 is used. The total amount of money that the investor has received in selling all the stocks since started trading in stock market is CGR 27,933.60 $(=13,348.80+4696.80+9888.0)$. The total amount of money that the investor has paid to buy all the stocks is CGR 27,100.16 $(=8089.60+7887.36+11,123.20)$. Therefore, the cumulative gain that the investor has obtained in investing in CHES is CGR 833.44 $(=27,933.60-27,100.16)$. Therefore, the CGT that is liable for this investor is CGR $83.34\left(=833.44^{*} 10 / 100\right)$. However, by December 31,2012 , the cumulative tax paid by this investor is CGR 206.86 (see Section 4.1). Therefore, the government is liable to pay the difference that amounts to CGR $123.52(=206.86-83.34)$. Using the web interface and the implemented approach, the investor will be displayed as shown in Figure 7.

\subsection{YES-NO-NO in Figure 2}

Table 5 shows the portfolio of investor-A on CHES. As shown, like in 2012 and 2013,

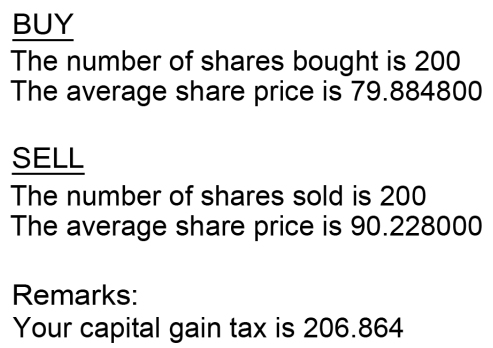

Figure 6. The outcome of YES-YES in Figure 2. 
the investor is able to sell all the stocks bought. Therefore, to tax this investor in 2014, the scenario-1 is used. The total amount of money that the investor has received in selling all the stocks since started trading in stock market is CGR $32,877.60(=13,348.80$ $+4696.80+9888.0+4944.00)$. The total amount of money that the investor has paid to buy all the stocks is CGR 37,112.16 $(=8089.60+7887.36+11,123.20+10,112.00)$. Therefore, the cumulative loss that the investor has obtained in investing in CHES is CGR -4234.56 $(=32,877.60-37,112.16)$. Therefore, the CGT that is liable for this investor is zero. However, by December 31,2013, the cumulative tax paid by this investor is CGR 83.34 (see Section 4.2). Therefore, the government is liable to pay CGR 83.34. Using the web interface and the implemented approach, the investor will be displayed as shown in Figure 8.

\subsection{NO-YES-YES in Figure 3}

The portfolio of investor-B, who opened an account to trade stocks in January 2012, is placed in Table 6. Table 6 shows this investor's transactions in one of the listed companies (BOSS). As shown, in 2012, the investor has bought 100 shares of BOSS. However, the investor has sold only 75 shares of BOSS. Therefore, the investor is left with 25 shares of BOSS unsold. The total amount of money raised in selling 75 shares of BOSS is CGR 11,124.00. However, the total amount of money that the investor has paid to buy 100 shares of BOSS is CGR 10,112.00. As per the above values, the investor has not met the conditions for the scenario-1. Therefore, the investor is conditioned as per scenario-2. In scenario-2, the investor is taxed if the total amount of money raised in selling shares (it is noted that the number of shares sold is not equal to number of shares bought) is greater than the total amount of money paid to buy shares. Therefore, the CGT for this investor in 2012 is CGR $101.20\left(=(11,124-10,112)^{\star} 10 / 100\right)$. Using the

\section{BUY \\ The number of shares bought is 300 \\ The average share price is 90.333867 \\ SELL \\ The number of shares sold is 300 \\ The average share price is 93.112000 \\ Remarks: \\ The amount of money owed by the govt is 123.52}

Figure 7. The outcome of YES-NO-YES in Figure 2.

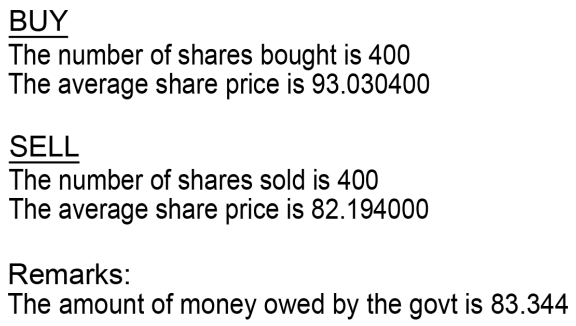

Figure 8. The outcome of YES-NO-NO in Figure 2. 
web interface and the implemented approach, the investor will be displayed as shown in Figure 9.

\subsection{NO-YES-NO in Figure 3}

The portfolio of investor-B on December 31, 2013 is placed in Table 7. As shown, the investor has made few transactions in 2013 as well. However, like in 2012, the investor has left few shares unsold. The total amount of money raised in selling shares (CGR $20,987.28=11,124+9863.28)$ is greater than the total amount of money paid to buy shares (CGR 20,224 $=10,112+10,112$ ). Therefore, the investor is conditioned as per scenario-2. The cumulative CGT that the investor is liable to pay is CGR 76.33 $\left((20,987.28-20,224)^{\star} 10 / 100\right)$. This amount is less than what was paid (CGR 101.20) by the investor in 2012 (see Section 4.4). Therefore, the government is liable to pay the difference that amounts to CGR 24.87 (=101.20 - 76.33). In other words, the investor shall receive CGR 24.87. Using the web interface and the implemented approach, the investor will be displayed as shown in Figure 10.

\subsection{NO-NO-YES in Figure 4}

The portfolio of investor-C, who opened an account to trade stocks in January 2012, is placed in Table 8. Table 8 shows this investor's transactions in one of the listed companies (RESS). As shown, in 2012, the investor has bought 100 shares of RESS. However, the investor has sold only 75 shares of RESS. Therefore, the investor is left with 25 shares of RESS unsold. The total amount of money raised in selling 75 shares of RESS is CGR 8157.6. However, the total amount of money that the investor has paid to buy 100 shares of RESS is CGR 10,112.00. As per the above values, the investor has not met

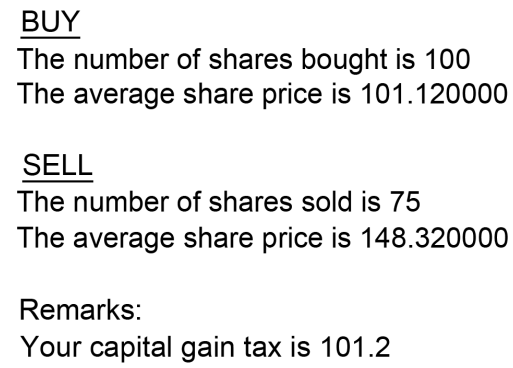

Figure 9. The outcome of NO-YES-YES in Figure 3.

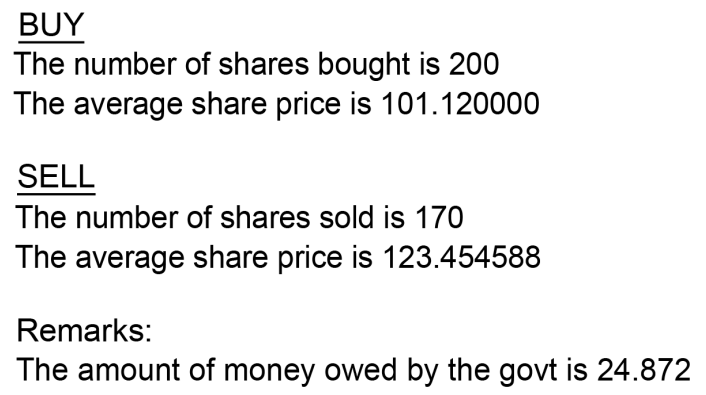

Figure 10. The outcome of NO-YES-NO in Figure 3. 
the conditions for scenario- 1 and scenario-2. Therefore, the investor is conditioned as per scenario-3. In scenario-3, the investor is taxed based on the market value of the remaining shares. Therefore, with a market price of CGR 90, the possible value of the remaining shares is CGR $2224.8\left(=25^{*}\left(90-90^{\star} 1.12 / 100\right)\right)$. Thus, the total amount of money raised in selling the 100 shares of RESS is CGR 10,382.4 $(=2224.8+8157.6)$. Therefore, the CGT for this investor in 2012 is CGR $27.04(=(10,382.4-10,112.00)$ $\left.{ }^{\star} 10 / 100\right)$. Using the web interface and the implemented approach, the investor will be displayed as shown in Figure 11.

\subsection{NO-NO-NO-NO in Figure 4}

The portfolio of investor-C on December 31, 2013, is placed in Table 9. As shown, the investor has not sold the remaining shares. However, compared to 2012, the share price of RESS has dropped to CGR 80. Therefore, the possible value of the remaining shares in 2013 is CGR 1977.6. The total amount of money raised in selling 100 shares of RESS is CGR 10,135.2 (=1977.6 + 8157.6). However, the total amount of money that the investor has paid to buy 100 shares of RESS is CGR 10,112.00. Therefore, the cumulative CGT that the investor is liable to pay is CGR $2.32\left(=(10,135.2-10,112.00)^{\star} 10 / 100\right)$. This amount is less than what was paid by the investor in 2012 (CGR 27.04). Therefore, the government is liable to pay the difference CGR $24.72(=27.04-2.32)$. In other words, the investor shall receive CGR 24.72. Using the web interface and the implemented approach, the investor will be displayed as shown in Figure 12.

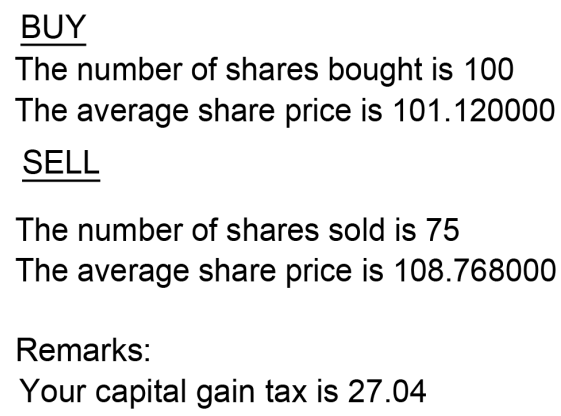

Figure 11. The outcome of NO-NO-YES in Figure 4.

BUY

The number of shares bought is 100

The average share price is 101.120000

SELL

The number of shares sold is 75

The average share price is 108.768000

Remarks:

The amount of money owed by the govt is 24.72

Figure 12. The outcome of NO-NO-NO-NO in Figure 4. 


\subsection{NO-NO-NO-YES in Figure 4}

The portfolio of investor-C on December 31, 2014, is placed in Table 10. As shown, the investor has not sold the remaining shares. However, compared to 2013, the share price of RESS has dropped to CGR 60. Therefore, the possible value of the remaining shares in 2014 is CGR 1483.2. The total amount of money raised in selling 100 shares of RESS is CGR $9640.8(=1483.2+8157.6)$. However, the total amount of money that the investor has paid to buy 100 shares of RESS is CGR 10,112.00. Therefore, the investor has incurred a loss in investing in RESS. The investor's loss amounts to CGR 471.2 $(=10,112.00$ - 9640.8). Therefore, the government is liable to pay CGR 2.32. This amount is the accumulated tax paid by the investor since 2012 (see Section 4.7). Using the web interface and the implemented approach, the investor will be displayed as shown in Figure 13.

\section{Conclusions and Recommendations}

Though in the past many attempts have been made to properly streamline the capital gain tax (CGT), the methodologies or the approaches used in the implementation of CGT, even in the United States, are not well-grounded from a scientific point of view. Therefore, in this paper, a simplified approach, which is easy-to-use, practical and un-biased, is proposed and tested using some hypothetical data. The proposed approach with the current technology will enhance the developing nations which have large size of informal economy, on designing and implementing effective tax policies and administrations. Furthermore, based on this study, the following points are highlighted:

1) The proposed approach will eliminate the existence of artificial market conditions. The major shareholders of listed companies or the surrogates of them and the largescale investors will be aware that an artificial appreciation in the share prices of the listed companies will force them to pay the CGT. On other hand, the ruling authorities will also be aware that an artificial drop in the share prices of the listed companies will make them to pay back the CGT received from the investors. Therefore, the proposed approach will pave the ruling authorities to implement a share market that is un-biased and sustainable.

\footnotetext{
$\underline{B U Y}$

The number of shares bought is 100

The average share price is 101.120000

$\underline{\text { SELL }}$

The number of shares sold is 75

The average share price is 108.768000

Remarks:

The amount of money owed by the govt is 2.32

Figure 13. The outcome of NO-NO-NO-YES in Figure 4.
} 
2) The proposed approach for implementing the CGT in stock marketing is based on an open access platform. However, the scalability of the proposed approach needs to be tested against the other commercial relational database management systems. This would become vital in a stock market with growing number of investors.

3) The proposed approach does not account for web securities. For example, in demonstrating the approach, the credentials to the database server were used without any encryptions. Therefore, the web security is one of the needs that have to be researched in-depth to account for reliability in the long run. The desktop version of the proposed approach is also an option that needs to be explored in the environment of security issues.

4) The proposed approach is based on the assumption that the CGT is implemented on a yearly basis. However, the interest or the opportunity cost that is incurred on a yearly basis is not accounted. For example, if an investor pays CGR 10 as the CGT in 2012 but incurs an accumulated loss of CGR 5 at the end of 2013, as per the proposed approach, the government is liable to pay back CGR 10 to the investor in 2013. However, the tax money that is paid by the investor in 2012 may have some opportunity cost. Therefore, there is a need to research on the applicability of an interest in paying back to the investor. This would become vital for large-scale investors.

5) The proposed approach is at stock level. In other words, the CGT is calculated for each listed companies owned by an investor or an institution. The proposed approach could be further researched and implemented at portfolio level of an investor or an institution.

6) The proposed approach with the web interface could be integrated with a mail server to automatically send the tax details to investors or institutions in a stock market. This would effectively enhance the security of the taxation system as it is housed and accessed only by the authorized officers, instead of the investors or institutions of a stock market.

7) In the proposed approach, a database is assigned for each investor in a stock market. This would become a vital point to be researched in a stock market with growing number of investors. Though there may be many options to overcome this, one of the potential options could be to store the account details (e.g., passport number) in a table and then link (using one-to-many relationship) the records in that table to other tables that store the transactions of shares. This will let the ruling authorities to house all the investors within a single database.

\section{Acknowledgements and Disclaimer}

The author is an alumnus of Texas A\&M University, Texas, USA. The views expressed here are solely those of the author in his private capacity and do not in any way represent the views of Texas A\&M University, Texas, USA.

\section{References}

[1] United Nations Development Programme (2015) Human Development Report 2015: Work 
for Human Development. Oxford University Press, New York.

[2] Bird, R.M. (2015) Improving Tax Administration in Developing Countries. Journal of Tax Administration, 1, 23-45.

[3] Bird, R.M. and Zolt, E. (2008) Technology and Taxation in Developing Countries: From Hand to Mouse. National Tax Journal, 61, 791-821. https://doi.org/10.17310/ntj.2008.4S.02

[4] D’Ascenzo, M. (2015) Global Trends in Tax Administration. Journal of Tax Administration, 1, 81-105. http://JoTA.website/article/view/15/30

[5] Ballard, C., Fullerton, D., Shoven, J.B. and Whalley, J. (2003) The Relationship between Tax Rates and Government Revenue. University of Chicago Press, Chicago.

[6] Lo, M. (2015) A Study on Lock-In Effect of Capital Gains Tax for Securities in Taiwan Stock Market-An Application of DID Model. Modern Economy, 6, 954-964. https://doi.org/10.4236/me.2015.69090

[7] Capital Gains Tax (2016). https://en.wikipedia.org/w/index.php?title=Capital_gains_tax\&oldid=749472830

[8] Tax (2016). https://en.wikipedia.org/w/index.php?title=Tax\&oldid=748801476

[9] Minarik, J.J. (2008) Taxation: The Concise Encyclopedia of Economics. Library of Economics and Liberty. http://www.econlib.org/library/Enc/Taxation.html

[10] Clemens, J., Lammam, C. and Lo, M. (2014) The Economic Costs of Capital Gains Taxes in Canada. Fraser Institute.

[11] Capital Gains Tax in the United States (2016). https://en.wikipedia.org/w/index.php?title=Capital_gains_tax_in_the_United_States\&oldid $=749559576$ 


\section{Appendix}

1. $<$ ?php

2.

3. if (isset(\$_POST['submit']))

4. \{

5.

6. \$companyCode $=\$$ \$_POST ['CODE'];

7. $\$$ NICCode $=\$$ \$POST['NIC'];

8. $\$$ CGTCode $=\$$ _POST['CGTR'];

9. $\$$ MktPrice $=\$ \_P O S T[' M k t P r i c e ']$;

10.

11. try \{

12.

13. $\quad$ \$mysqlhost = "localhost";

14. $\$$ mysqluser $=$ "root";

15. \$mysqlpass = "';

16. $\$$ rateCGT $=\$$ CGTCode;

17. $\$$ stockCode $=\$$ companyCode;

18. \$stockCommission=1.12;

19.

20. if $(\$ \mathrm{db}=$ mysql_connect (\$mysqlhost, $\$$ mysqluser, $\$$ mysqlpass $))\{$

21. mysql_select_db(\$NICCode);

22.

23. $\$$ query $=$ "SELECT sum(Amount)/sum(NShares), sum(NShares), sum(Amount) FROM ".\$stockCode." WHERE Type='B"';

24. $\quad$ \$result $=$ mysql_query $(\$ q u e r y) ;$

25. \$buyAverage = mysql_result( (\$result, 0, "sum(Amount)/sum(NShares)");

26. \$buyShares = mysql_result (\$result, 0 , "sum(NShares)");

27. \$buyTotal = mysql_result $(\$$ result, 0 , "sum(Amount)");

28.

29. echo " $<\mathrm{B}><\mathrm{u}>\mathrm{BUY}</ \mathrm{u}></ \mathrm{B}><\mathrm{BR} />$ ";

30. echo "The number of shares bought is ".\$buyShares;

31. echo " $<\mathrm{BR} />$ ";

32. echo "The average share price is ".\$buyAverage;

33. echo " $<\mathrm{BR} /><\mathrm{BR} />$ ";

34.

35. $\$$ query $=$ "SELECT $\operatorname{sum}($ Amount $) /$ sum(NShares), sum(NShares), sum(Amount) FROM ".\$stockCode." WHERE Type='S"';

36. $\quad$ \$result $=$ mysql_query $($ query);

37. \$sellAverage $=$ mysql_result $($ \$result, 0 , "sum(Amount)/sum(NShares)");

38. \$sellShares = mysql_result( $($ result, 0 , "sum(NShares)");

39. $\quad$ \$sellTotal $=$ mysql_result $($ \$result, 0 , "sum(Amount)"); 
40.

41. echo " $<\mathrm{B}><\mathrm{U}>\mathrm{SELL}</ \mathrm{U}></ \mathrm{B}><\mathrm{BR} />$ ";

42. echo "The number of shares sold is ".\$sellShares;

43. echo "<BR/>";

44. echo "The average share price is ".\$sellAverage;

45. echo " $<\mathrm{BR} /><\mathrm{BR} />$ ";

46.

47. \$query = "SELECT CumulativeTaxPaid FROM taxinfo WHERE Company="'.\$stockCode."'";

48. $\quad$ \$result $=$ mysql_query $($ \$query $)$;

49. \$taxPaid = mysql_result(\$result, 0, "CumulativeTaxPaid");

50.

51.

52. if $((\$$ sellShares-\$buyShares $)==0)\{$

53. \$totalGainLoss $=\$$ sellTotal $-\$$ buyTotal;

54. $\$ \mathrm{CGT}=\$$ totalGainLoss ${ }^{\star} \$$ rateCGT $/ 100$;

55.

56. if $(\$ C G T>\$$ taxPaid $)\{$

57. $\quad$ echo " $<\mathrm{B}>$ Remarks: $</ \mathrm{B}><\mathrm{BR} />$ ";

58. \$CGTUpdated $=\$ C G T-\$$ taxPaid;

59. echo "Your capital gain tax is ".\$CGTUpdated;

60. \$taxNewPaid=\$CGT;

61. $\$$ \$query = "UPDATE 'taxinfo' SET 'CumulativeTaxPaid $="$.\$taxNewPaid." WHERE company="'.\$stockCode."'";

62. $\quad$ \$result $=$ mysql_query $($ \$query $)$

63. $\quad$ echo " $<\mathrm{BR} />$;

64. $\quad$ echo " $<\mathrm{BR} />$ ";

65. $\}$

66. else \{

67. $\quad$ if $(\$ C G T>0)\{$

68. $\quad$ echo " $<\mathrm{B}>$ Remarks: $</ \mathrm{B}><\mathrm{BR} />$ ";

69. \$CGTUpdated $=\$$ taxPaid $-\$ C G T$;

70. $\quad$ echo "The amount of money owed by the govt is ".\$CGTUpdated;

71. \$taxNewPaid=\$CGT;

72. $\$$ query = "UPDATE `taxinfo `SET `CumulativeTaxPaid `=".\$taxNewPaid." WHERE company="'.\$stockCode."'";

73. $\quad$ Sresult $=$ mysql_query $($ \$query $)$;

74. $\quad$ echo "<BR/>";

$75 . \quad$ echo " $<\mathrm{BR} />$ ";

76. $\}$

77. else \{

78. $\quad$ echo " $<\mathrm{B}>$ Remarks: $</ \mathrm{B}><\mathrm{BR} />$ "; 
79. $\quad \$ C G T U$ pdated $=\$$ taxPaid;

80. echo "The amount of money owed by the govt is ".\$CGTUpdated;

81. $\quad \$$ taxNewPaid $=0$;

82. $\quad$ \$query = "UPDATE `taxinfo`SET `CumulativeTaxPaid`=".\$taxNewPaid." WHERE company="'.\$stockCode."'";

83. $\quad$ Sresult $=$ mysql_query $($ \$query $)$;

84. $\quad$ echo " $<\mathrm{BR} />$ ";

85. $\quad$ echo " $<\mathrm{BR} />$ ";

86.

87. $\quad\}$

88. $\}$

89.

90.

91. \}

92. elseif $(\$$ sellTotal $>$ \$buyTotal $)\{$

93. \$totalGainLoss $=\$$ sellTotal- $\$$ buyTotal;

94. $\$ \mathrm{CGT}=\$$ totalGainLoss ${ }^{\star} \$$ rateCGT/100;

95.

96. if $(\$ C G T>\$$ taxPaid $)\{$

97. echo " $<$ B $>$ Remarks: $</ \mathrm{B}><\mathrm{BR} />$ ";

98. $\quad \$ C G T U$ pdated $=\$ C G T-\$$ taxPaid;

99. echo "Your capital gain tax is ".\$CGTUpdated;

100. \$taxNewPaid=\$CGT;

101. \$query = "UPDATE `taxinfo`SET `CumulativeTaxPaid`=".\$taxNewPaid." WHERE company="'.\$stockCode."'";

102. $\quad$ \$result $=$ mysql_query $($ query);

103. echo " $<$ BR/>";

104. echo " $<\mathrm{BR} />$ ";

105. \}

106. else \{

107. $\quad$ echo " $<$ B $>$ Remarks: $</ \mathrm{B}><\mathrm{BR} />$ ";

108. $\$$ CGTUpdated $=\$$ taxPaid $-\$ C G T$;

109. echo "The amount of money owed by the govt is ".\$CGTUpdated;

110. $\$$ taxNewPaid $=\$ C G T$;

111. \$query = "UPDATE `taxinfo`SET `CumulativeTaxPaid`=".\$taxNewPaid." WHERE company="'.\$stockCode."'";

112. \$result = mysql_query (\$query);

113. echo " $<\mathrm{BR} />$;

114. echo " $<\mathrm{BR} />$ ";

115.

116. \} \}

117. else 
118. \{

119. \$remainingShares $=\$$ buyShares $-\$$ sellShares;

120. $\$$ PossibleValue $=(\$ M k t P r i c e-\$ M k t P r i c e * \$ \text { stockCommission } / 100)^{*} \$$ remainingShares;

121. \$totalGainLoss $=\$$ sellTotal $-\$$ buyTotal $+\$$ PossibleValue;

122. $\$ \mathrm{CGT}=\$$ totalGainLoss ${ }^{\star} \$$ rateCGT $/ 100$;

123.

124. if $($ \$CGT $>$ \$taxPaid $)\{$

125. echo " $<$ B $>$ Remarks: $</ \mathrm{B}><\mathrm{BR} />$ ";

126. \$CGTUpdated $=\$ C G T-\$$ taxPaid;

127. echo "Your capital gain tax is ".\$CGTUpdated;

128. \$taxNewPaid=\$CGT;

129. \$query = "UPDATE `taxinfo`SET `CumulativeTaxPaid`=".\$taxNewPaid." WHERE company="'.\$stockCode."'";

130. $\quad$ \$result $=$ mysql_query $($ query);

131. echo " $<\mathrm{BR} />$ ";

132. $\quad$ echo " $<\mathrm{BR} />$ ";

133. \}

134. else\{

135. if $(\$ C G T>0)\{$

136. $\quad$ echo " $<$ B $>$ Remarks: $</ \mathrm{B}><$ BR $/>$ ";

137. $\$$ CGTUpdated $=\$$ taxPaid $-\$ C G T$;

138. echo "The amount of money owed by the govt is ".\$CGTUpdated;

139. $\$$ taxNewPaid $=\$ C G T$;

140. \$query = "UPDATE 'taxinfo' SET `CumulativeTaxPaid`=".\$taxNewPaid." WHERE company="'.\$stockCode."'";

141. \$result = mysql_query (\$query);

142. $\quad$ echo " $<\mathrm{BR} />$;

143. $\quad$ echo " $<\mathrm{BR} />$ ";

144. \}

145. else\{

146. $\quad$ echo " $<$ B $>$ Remarks: $</ \mathrm{B}><$ BR $/>$ ";

147. \$CGTUpdated $=\$$ taxPaid;

148. echo "The amount of money owed by the govt is ".\$CGTUpdated;

149. $\$$ taxNewPaid $=0$;

150. $\$$ query = "UPDATE 'taxinfo' SET 'CumulativeTaxPaid’=".\$taxNewPaid." WHERE company="'.\$stockCode."'";

151. $\quad$ \$result $=$ mysql_query $($ \$query);

152. $\quad$ echo " $<\mathrm{BR} />$ ";

153. $\quad$ echo " $<\mathrm{BR} />$ ";

154.

155. $\quad\}$ 
156. $\}$

157. \}

158.

159. mysql_close $(\$ d b)$;

160.

161. \} else \{

162. throw new exception ("Sorry, could not connect to mysql.");

163. \}

164. $\}$ catch (exception $\$$ e) \{

165. echo \$e->getmessage ();

166.\}

167.

168.

169.

170.?>

171.

172.

173. $<$ HTML $>$

174. $<$ form action=" $<$ ?=\$_SERVER['PHP_SELF']?>" method="post" $>$

175.

176. <table style="width: $100 \%$, text-align:center">

177.

178. $\quad<\operatorname{tr}>$

179. $<\mathrm{td}>$ Passport Number $</ \mathrm{td}>$

180. $<$ td $><$ input name="NIC" type="text" style="width: 300px" $\mid><$ br $\mid></$ td $>$

181. $</$ tr $>$

182. $<\operatorname{tr}>$

183. $<\mathrm{td}>$ Company Code $</ \mathrm{td}>$

184. $<\mathrm{td}><$ input name="CODE" type="text" style="width: 300px" $/><$ br $/></ \mathrm{td}>$

185. $</ \operatorname{tr}>$

186.

187. $<$ tr $>$

188. $<\mathrm{td}>$ Market Price $</ \mathrm{td}>$

189. $<$ td $><$ input name="MktPrice" type="text" style="width: 300px" $\mid><$ br $/></$ td $>$

190. $</ \operatorname{tr}>$

191.

192. $<\operatorname{tr}>$

193. $<\mathrm{td}>$ CGT Rate $</ \mathrm{td}>$

194. $<$ td $><$ input name="CGTR" type="text" style="width: 300px" value="10" $/><$ br $1></ \mathrm{td}>$

195. $</$ tr $>$

196. 
197. $<\operatorname{tr}>$

198. $<\mathrm{td}></ \mathrm{td}>$

199. $<\mathrm{td}><$ input style="width: 130px; height: 30px" type="submit" name="submit" value $=$ "Compute CGT" $/><$ br $/></$ td $>$

200. $</ \operatorname{tr}>$

201. $</$ table $>$

202.

203. $</$ form $>$

204.

205. $</$ HTML $>$

Submit or recommend next manuscript to SCIRP and we will provide best service for you:

Accepting pre-submission inquiries through Email, Facebook, LinkedIn, Twitter, etc. A wide selection of journals (inclusive of 9 subjects, more than 200 journals)

Providing 24-hour high-quality service

User-friendly online submission system

Fair and swift peer-review system

Efficient typesetting and proofreading procedure

Display of the result of downloads and visits, as well as the number of cited articles Maximum dissemination of your research work

Submit your manuscript at: http://papersubmission.scirp.org/

Or contact ojapps@scirp.org 